\title{
What influences doctors to work in rural locations?
}

\author{
Student background and clinical education act synergistically
}

W e are fortunate that there is increasing evidence available on which to base policy decisions for building the rural medical workforce. The concept of the rural pipeline $e^{1}$ provides a framework in which to consider who we admit to medical programs, where we can best deliver medical education that is motivating towards rural practice and why graduates then choose to work in rural locations.

Medical

school debt

and financial

incentives

potentially

also influence

decisions

regarding

rural practice

Judith N Hudson

BMBS, MSc, PhD

Jennifer A May

BMed(Hons), FRACGP, FACRRM

University of Newcastle,

Tamworth, NSW.

nicky.hudson@

newcastle.edu.au

doi: 10.5694/mja14.01550

Research p 41, 46

Online first 12/1/15
Two new sources of evidence are helping to address the "who" and "where" considerations. The Medical Schools Outcomes Database and Longitudinal Tracking (MSOD) Project has provided evidence of medical student career graduate education, and data on location of practice in the early postgraduate years. In this issue of the Journal, Hays and colleagues describe their analysis of national MSOD data to determine where full-fee paying (FFP) students intend to practise. ${ }^{2}$ They conclude that FFP students are significantly more likely to practise in an urban area.

Their findings should cause us to pause and reflect on the question of who to admit. If we no longer have a shortage of medical practitioners in Australia (compared with other OECD [Organisation for Economic Co-operation and Development] countries ${ }^{3}$ ) but the challenge of distributing practitioners to rural areas is ongoing, FFP students with urban practice intentions are not likely to help address the maldistribution challenge.

Also in this issue, Kondalsamy-Chennakesavan and colleagues, who studied determinants of rural practice in University of Queensland medical graduates, ${ }^{4}$ affirmed that rural background is one of the greatest predictors of rural practice. ${ }^{5}$ Owing to the maturity of the University of Queensland Rural Clinical School (UQRCS) program, the authors could show a direct relationship between length of rural background (before medical school entry) and likelihood of rural practice. Those who had attended UQRCS as undergraduates for 1-2 years had increased odds of rural practice, and more time spent at UQRCS increased the odds. The effect of rural background plus rural undergraduate clinical education was also affirmed as very influential for recruiting future rural practitioners. 4

We now need to build on these promising findings from over a decade of federal government support for the Rural Clinical Training and Support program and explore why graduates go on to practise in rural locations. The next stage in the vertical continuum of the medical education pipeline, including the social issues that affect practice location, surely deserves attention.

Postgraduate education occurs at a crucial time in a trainee's personal and professional life. For most specialties, this training is currently based in large urban centres, intentions on commencement and completion of under- and trainees spend very little time in rural settings. Thus mentor-trainee relationships, life partnerships, work opportunities for partners, purchases of homes, and stable child care or schooling arrangements become established in urban centres.

Reversing this trend offers promise of influencing trainees to train in rural locations and then remain there. This may be attractive to older or married students, who are more likely to choose a rural location. ${ }^{4}$ The considerable investment in infrastructure and human resources for undergraduate education in rural Australia can then be leveraged to build regional local postgraduate training networks. Start-up funding will help establish the necessary partnerships with postgraduate training providers and colleges for regionally based postgraduate education.

Medical school debt and financial incentives potentially also influence decisions regarding rural practice. Hays et al highlight the large debts that many FFP students incur by graduation, and suggest that these might motivate choice of urban practice in lucrative subspecialties. ${ }^{2}$ In the future, increasing debts incurred by Commonwealthsupported place (CSP) students, owing to proposed changes to the HECS-HELP scheme (Higher Education Contribution Scheme, Higher Education Loan Program), might dissuade doctors from working in rural locations and in the needed vocation of general practice, despite the HECS Reimbursement Scheme for rural service. ${ }^{7}$ Evidence for the influence of medical school selection on rural medical workforce is growing. Recruiting CSP students from rural and lower socioeconomic backgrounds may prove to be an influential strategy.

Proposed changes to the District of Workforce Shortage, Australian Standard Geographical Classification Remoteness Area (ASGC-RA) system and Bonded Medical Places Scheme should encourage more doctors to work in rural locations. The Modified Monash Model (MMM) - the updated geographical classification system) will focus support and resources on small rural and remote communities (where the need is greatest), and any bonded student will be able to complete their return of service obligation in any small town $(<15000$ population). Application of MMM classifications to the General Practice Rural Incentives Programme is planned to ensure that incentive payments are targeted to relocating doctors to the areas of most need and retaining them there. Better targeting of incentives should provide a synergistic strategy ${ }^{9}$ and, when used in conjunction with key strategies associated with rural background, rural education and rural service obligations, should increase the number of doctors working in rural locations.

Competing interests: No relevant disclosures.

Provenance: Commissioned; externally peer reviewed. 
1 Mason J. Review of Australian Government workforce programs. Canberra: Department of Health, 2013. https:// www.health.gov.au/internet/main/publishing.nsf/Content/ work-health-workforce-program-review (accessed Dec 2014).

2 Hays RB, Lockhart KR, Teo E, et al. Full medical program fees and medical student career intention. Med J Aust 2015; 202: 46-49.

3 Organisation for Economic Co-operation and Development. OECD health statistics 2014. How does Australia compare? http://www.oecd.org/els/health-systems/Briefing-NoteAUSTRALIA-2014.pdf (accessed Nov 2014).

4 Kondalsamy-Chennakesavan S, Eley DS, Ranmuthugala G, et al. Determinants of rural practice: positive interaction between rural background and rural undergraduate training. Med J Aust 2015; 202: 41-45.

5 Jones M, Humphreys JS, McGrail MR. Why does a rural background make medical students more likely to intend to work in rural areas and how consistent is the effect? Aust $J$ Rural Health 2012; 20: 29-34.
6 Clark TR, Freedman SB, Croft AJ, et al. Medical graduates becoming rural doctors: rural background versus extended rural placement. Med J Aust 2013; 199: 779-782.

7 National Rural Health Alliance. Submission to the Senate Education and Employment Legislation Committee Inquiry into the Higher Education and Research Reform Amendment Bill 2014. http://ruralhealth.org.au/sites/default/files/ documents/nrha-policy-document/submissions/sub-highereducation-reform-bill-29-sep-2014.pdf (accessed Nov 2014).

8 Puddey IB, Mercer A, Playford DE, et al. Medical student selection criteria as predictors of intended rural practice following graduation. BMC Med Educ 2014; 14: 218.

9 Australian Government Department of Health. Rural recruitment and retention strategies. http://www.health. gov.au/internet/publications/publishing.nsf/Content/ work-review-australian-government-health-workforceprograms-toc $\sim$ chapter-4-addressing-health-workforceshortages-regional-rural-remote-australia chapter-4-ruralrecruitment-retention-strategies (accessed Nov 2014). 